\title{
Depicted welfare-recipient stereotypes in Norway and Denmark: a photo-elicitation study
}

\author{
Sofie Dencker-Larsen* \\ SFI - The Danish National Centre for Social Research \\ University of Copenhagen, Copenhagen, Denmark \\ Email: $\underline{\text { sdl@sfi.dk }}$ \\ *corresponding author
}

\author{
Kjetil G. Lundberg \\ The Uni Research Rokkan Centre \\ Bergen, Norway \\ Email: Kjetil.lundberg@uni.no
}

\begin{abstract}
Welfare recipients are continuously subjected to media debates and governmental campaigns drawing on images and symbols encouraging improved work ethic and individual responsibility. Only few studies, however, have analysed how welfare recipients as 'othered' citizens react to these often stereotypical symbols and images targeting them. In this study we have investigated how welfare recipients in Norway and Denmark, and caseworkers in Denmark, understand and account for images which, through the use of stereotypes, directly or indirectly may question welfare recipients' work ethic and deservedness. Analysing photo-elicitation interview data, we have uncovered a variety of reactions characterized by 'problematization'. The interviewees problematize the image and depicted stereotypes, which they link both with motif and symbols and with surrounding public debates on the work ethic and deservedness of welfare recipients. Furthermore, as photo-elicitation is a rarely used tool in welfare research, we address methodological aspects of using photo-elicitation in a study of 'othered' welfare recipients.
\end{abstract}

Keywords: welfare recipients, stereotypes, work ethic, photo-elicitation, visual culture, visual methods 


\section{Introduction}

Welfare, work ethic, and individual responsibility are hot topics of public debate in Nordic welfare states (Hedegaard, 2014; Larsen \& Dejgaard, 2012; Lundberg, 2012). Experts, policy-makers, and other media actors continuously present images that, on the one hand, encourage citizens to be healthy, active, and responsible for their own well-being, and, on the other hand, discourage stereotypical 'otherness', which is linked with amoral attitudes and behaviour. Stereotyping others is a social process that can be understood as a 'form of labelling, which attains a taken-for-granted quality and serves to portray particular social groups as homogenous. It is a discursive strategy that magnifies and distorts difference' (Lister, 2004, p. 101). Like Lister, we view stereotypes mediated through language and images as closely related to 'othering' practices that instil boundaries between 'us' and 'them'. For social scientists, the emerging field of visual studies offers tools for exploiting the visual medium by integrating it in research (e.g., Bagnoli, 2009; Margolis \& Pauwels, 2011; Rose, 2012; Spencer, 2011). Few studies, however, have used visual methods to explore how citizens on the 'ground level' of welfare services, 'welfare subjects' and employees in welfare agencies, experience and react to depictions of 'others'. In this study we aim to do exactly that. Using images in qualitative interviews, we investigate how welfare recipients and caseworkers understand and account for stereotypical depictions of welfare recipients' work ethic and deservedness. Our analysis is based on merged interview data from one Norwegian and one Danish research project. In both research projects we conducted lifeworld-focused, narratively informed qualitative interviews with welfare recipients (and in the Danish study also with caseworkers). During the interviews we presented the interviewees with images containing potential stereotypes of welfare recipients and individual-responsibility discourse, and asked them to comment on them. This is a technique called photo-elicitation (PE) (see Harper, 1988, 2002; Rose, 2012). PE is a visual method 'based on the simple idea of inserting a photograph into a research interview' (Harper, 2002, p. 13). Despite not being widely used in studies of 'othered' welfare recipients, $\mathrm{PE}$ is used in interview studies on related topics, including research on poor and vulnerable groups (e.g., Martin, 2012; Ornelas et al., 2009; OrtegaAlcàzar \& Dyck, 2012; Radley \& Taylor, 2003), often in search of reflexivity and participation of research subjects (e.g. Ortega-Alcàzar \& Dyck, 2012; Rose, 2012).

The images we chose for PE are a photograph of Robert Nielsen, also known as 'Lazy Robert' ('Dovne Robert') from Denmark and a print advertisement from the 'Faster Back' ('Raskere Tilbake') campaign from Norway. The images themselves are dissimilar, and they work in two different national settings, but both images channel stereotypical depictions of welfare recipients' work ethic and deservedness. We have analysed data from PE interviews with individuals situated at the ground level of welfare services. In the following section we present and contextualize the two images. We then present our analytical strategy, including methods and data. We divide our analysis into three parts: i) problematizations related to the Danish image; ii) problematizations related to the Norwegian image; and iii) examples of non-problematization. Finally, we discuss how meaning is constructed in and from the two images in complex and often overlapping ways connected to issues of self-presentation and stereotypical portrayals of welfare recipients' work ethic and deservedness, and to methodological points concerning the use of PE in a study of 'othered' citizens. 


\section{Nordic depictions of welfare recipients' work ethic and deservedness}

The analysis is situated in two specific national settings belonging to the same family of welfare-state systems. Both Denmark and Norway have welfare-state models which combine comparatively generous welfare-state benefit levels with Active Labour Market Policies. Policy reforms and organizational reforms have been implemented in both countries since the millennium shift and activation policies have been expanded. Welfare benefits and welfare recipients remain intense topics of debate in both countries. In our research projects we included $P E$ interviews and chose images which we interpreted as connected to broader social policy issues concerning welfare recipients. Beginning with the photograph of Danish citizen Robert Nielsen, we present and contextualize the two images used in this article.

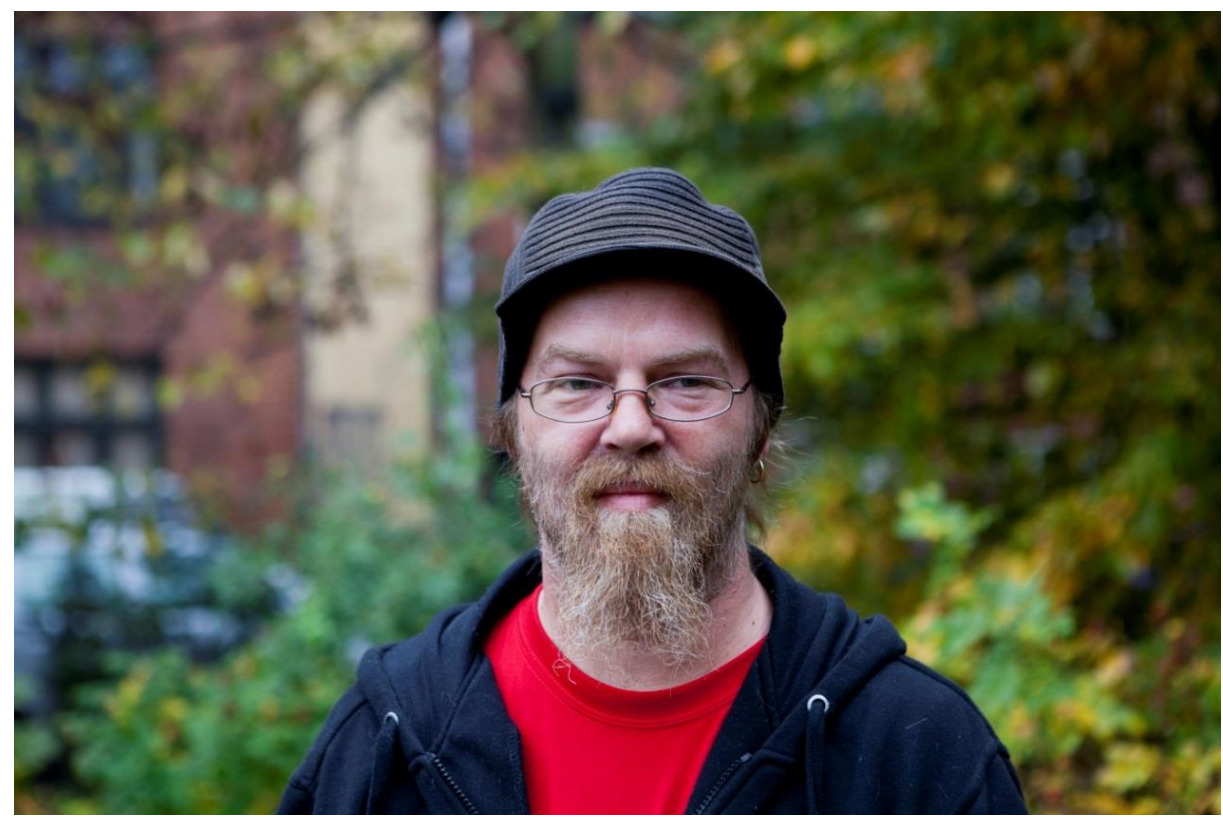

Figure 1: Photograph of Robert Nielsen

Copyright: Henrik Moberg Jessen Photography

A long-term unemployed person, Robert Nielsen (RN), became famous and a catalyst of intense public and political debate in Denmark during the autumn of 2012 after being interviewed on the debate television programme On the other side ('På den 2. side'). RN publicly described himself as lazy, saying that he preferred receiving welfare benefits rather than working at McDonald's or accepting other low-skilled jobs that he felt, from experience, insulted him as both a citizen and a human being (DR, September 21, 2012; DR, September 8 , 2012). The press swiftly named him 'Lazy Robert', and his television appearance sparked extensive political debate concerning the legitimacy of welfare recipients (see Hedegaard, 2014). This debate occurred in the aftermath of the 2008 financial crisis when Denmark experienced an increase in unemployment rates. According to The New York Times, who introduced an American audience to RN, the debate concerned 'whether their (the Danes') beloved welfare state, perhaps Europe's most generous, had become too rich, undermining the country's work ethic' (Daley, 2013, April 20; see also Hedegaard, 2014). The debate was extensive, and readers of the DR's online news site voted the term 'Lazy Robert' the 2012 'news expression of the year' (Pinholt, 2014, March 27). 
Despite the image not containing any direct symbols of work ethic and deservedness, it portrays $\mathrm{RN}$ who, as we show above, is frequently linked with the label 'Lazy Robert'. The label thus originated from a person, but is often used as a symbol on its own. 'Lazy Robert' has become an influential symbol in Denmark. In public and media debates, top-level politicians use the symbol as a depiction of welfare recipients when discussing unemployment issues (Hedegaard, 2014). Although the photograph does not directly contain symbols, the extensive media debate has caused the motif of RN, and the link to the 'Lazy Robert' label, to become a symbol on its own.

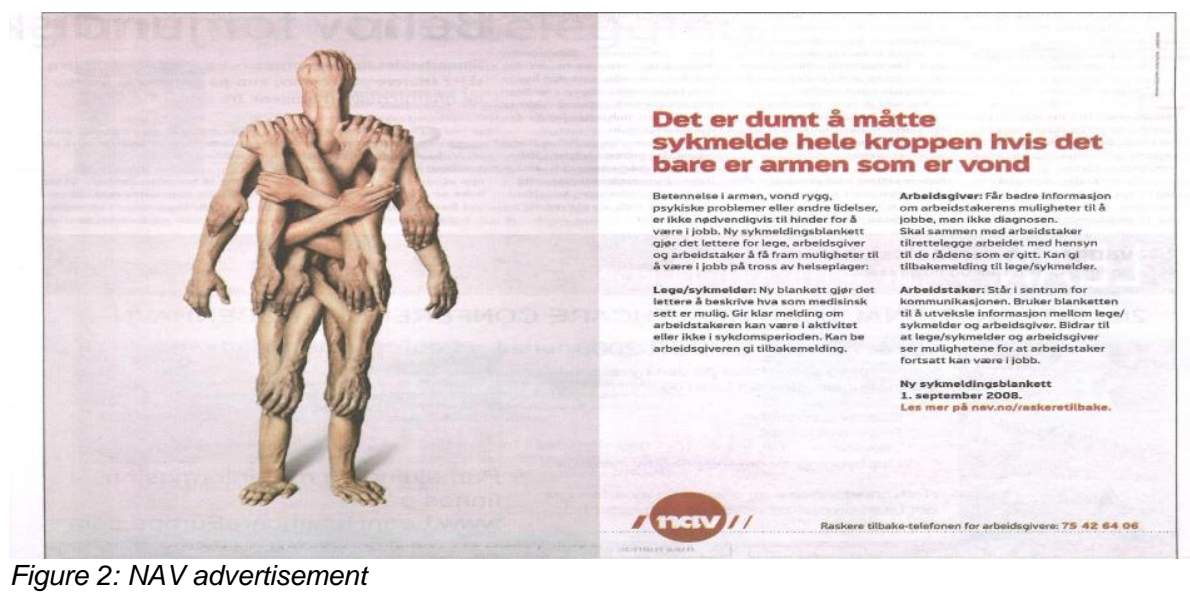

The second image in the PE study is part of an autumn 2008 advertisement campaign conducted by the Norwegian Employment and Welfare Administration (NAV) in newspapers, cinemas, and online. The campaign, named 'Faster Back', targets employees receiving sick-leave benefits and their employers. The advertisement is illustrated by a human-shaped figure consisting of hands and arms. The advertisement's headline tells the reader that 'It is dumb to put the whole body on sick leave, if it is only the arm that hurts.' In November 2008, this advertisement won a prize for being particularly effective in its communication to its target audience (see Lundberg, 2012).

The advertisement encourages employers and employees to shift their focus from health-related issues and barriers to coping strategies that can assist the individual's return to employment. It combines and depicts symbols of the individual and his or her problems and options and encourages the employee to revisit his or her ability to work full- or part-time. We view the campaign and the advertisement as soft measures for preventing or reducing sick leave and as a governmental empowerment strategy (Cruikshank, 1999; Mik-Meyer \& Villadsen, 2012), subjecting citizens to specific ideas and practices of handling and solving their individual problems and taking responsibility for their return to work. Thus, the advertisement encourages increased inclusion in the labour market, on the one hand, and targets the individual and his or her work ethic, on the other hand.

\section{Analytical strategy}

Depictions and media images are omnipresent in contemporary societies. Advertisements and images directly and indirectly channel discourses on how the viewer should behave, look, and lead his or her life. We chose the two images as potentially powerful images at the centre of on-going welfare debates. The Norwegian advertisement was featured in various media sources 
when the Norwegian interviews were conducted in 2009 and 2010. The sender of the image was the Norwegian welfare-state institution NAV. NAV is a 'onestop shop' agency that handles most benefits and contact with benefit recipients in the Norwegian welfare system. The image addressed welfare recipients directly and encouraged a revision of their status as recipients of sick leave. The motif of RN was frequently featured in Danish media concerning debates on unemployment and welfare recipients and used as a symbol of welfare recipients especially from 2012 to 2013. The image of RN did not have a clear sender. High-profile politicians, media commentators, and RN himself took part in various ways in distributing the image and symbol of 'Lazy Robert'. The two images are visually dissimilar and stem from different sources, but both are embedded in a discourse of individual responsibility in which there are expectations of individual responsibility in the work ethic of welfare recipients.

Photographs and images are polycentric (Barthes, 1981); they are un-coded messages that have multiple potential meanings and may be interpreted in many ways. The purpose of using PE is to analyse the interviewee's response to the image and his or her opinions and values related to the image topic(s). Harper (2002, p. 13), a key contributor to the development of PE, explains the difference between traditional interviews and those using images and text as related to how people respond to these different forms of communication. The strengths of $\mathrm{PE}$ include the possibility of enabling of tacit and native knowledge (Harper, 2002, 1988) and of enabling further investigation into the visual and sensory dimensions of experience (Bagnoli, 2009). According to advocates of $\mathrm{PE}$, it offers an alternative or complementary 'medium of communication that can open up issues that might escape the spoken word' (Ortega-Alcàzar \& Dyck, 2012, p. 109).

Meaning-making is context-dependent and audience-driven; images can therefore be understood in various ways (Grosvenor \& Hall, 2012). Fink and Lomax (2012) emphasize how PE enables dialogue among context, text, and image. They also highlight 'the importance of understanding inequality through the essentializing and stereotyping discourses by which welfare subjects are constituted' (Fink and Lomax 2012, p. 3). These discourses, they argue, can be identified, problematized and negotiated through the visual. Fink and Lomax find that PE and related methodological techniques invite collaborative dialogue between researchers and interviewees in which knowledge is created through a relational process of interpretation and negotiation. Thus, a dialogue of the visual through PE, for example, can function as 'a strategy for acknowledging the hierarchical power relations in the research process while embedding reflexivity at the core of their (the researchers') research practices in order that knowledge is produced with rather than about their participants' (Fink \& Lomax, 2012, p. 6). Similarly, Ortega-Alcàzar and Dyck (2012, p. 108) view PE as a medium for creating subject-centred accounts that 'can be invaluable in breaking down dominant discursive constructions of 'othered' groups'.

The specific images that we selected are loaded with symbols that may implicitly question the legitimacy of the interviewees' position and deservedness as recipients of welfare benefits. As is thoroughly established in the qualitative research literature, the interview situation can be an arena of impression management and the 'presentation of self' (Goffman, 1969; Silverman, 2001). A key tradition that has dealt with understanding people's responses to explicit or potential accusations is the sociology of accounts (Järvinen, 2001; Orbuch, 1997; Scott \& Lyman, 1968). Scott and Lyman (1968, p. 46) describe accounts as 'a linguistic device employed whenever an action is subjected to valuative inquiry'. Regarding rituals of speech they theorize that people use accounts when feeling pressured, accused, questioned or blamed. Building on insights 
from Austin (1957), they emphasize that accounts can take the form of 'excuses and justifications', two forms of linguistic strategies of defending one's position or action. Being accused or potentially accused of something means facing 'valuative inquiry', which is a common occurrence in most people's lives. However, knowing precisely when someone feels accused is not necessarily straightforward. Because these issues may be relevant to the welfare recipients' (and caseworkers') responses, we address them in the discussion.

Our study represents a merged Norwegian and Danish research project with concurrent focus and analytical objectives combined after the collection of the Norwegian data and during the collection of the Danish data. The Norwegian research project explored experiences of welfare recipients receiving unemployment and health benefits during a significant organizational reform of welfare services in Norway (see Lundberg, 2012). The Norwegian project comprises of interviews with a total of 29 welfare recipients (2009-2010). The Danish research project (2013-2014) is part of a mixed-methods investigation into unemployment, re-employment, and well-being of unemployed persons. The research project comprises ten interviews: five interviews with current or previous recipients of unemployment benefits and five interviews with caseworkers working in Danish job centres. Danish job centres handle the casework related to unemployed persons and other welfare recipients, and are equivalent to NAV. In both research projects we conducted lifeworld-focused, narratively informed qualitative interviews. In the Danish study PE was introduced from the third interview and consistently used in each of the following interviews (five of the welfare-recipient interviews, and three of the caseworker interviews). We used PE in the five first interviews of the Norwegian study until one interviewee reacted emotionally stressed and began to cry after seeing the image. This caused a discontinuation of using PE for the following interviews. We recognize that the two images may activate sensitive issues for interviewees. This consideration affected the development of both studies' datacollection strategy. It did not, however, cause interviewees with certain characteristics to be presented with the images. The research projects have been reported to and approved by the Norwegian Social Data Services (NSD) and national institution of research ethics and the Danish Data Protection Agency, respectively.

The PE components of the interviews were shorter parts of lengthy conversations regarding experiences with health, unemployment, welfare encounters, and the future. We introduced the interviewees to the images during the middle or last part of the interview when the flow of the interview had been established, and the interviewer had obtained an overview of the interviewee's experiences. When presenting the image to the interviewee, we simply asked them to comment on and to give us their thoughts of the image. We wanted the interviewee to comment on the image as freely as possible. In some cases, we named the campaign or motif, or briefly presented the image. In both of our research projects, we remained open to interviewee interpretations and categories by exploratively including PE, allowing the interviewees to form the discussion on the basis of their perception of the images. Furthermore, the stereotypes associated with both images are consistent with the overall themes of the interviews.

In the merged study, we read the parts of the interview in which the PE technique was used, and repeatedly discussed the merged PE data, seeking meaning-bearing commonality and discord. In the Danish case, the accounts by the caseworkers and the welfare recipients were strikingly, and surprisingly, similar. Overall, the interviewee accounts from both countries were varied, but showed strong commonalities between accounts activated in the PE interviews 
that could be grasped through the term 'problematization'. Hence, secondly, we used 'problematization' as a sensitizing concept (Blumer, 1969, p. 148) through which to give direction to the analysis, guiding the following rounds of our reading and discussions of the PE interview data and analytical findings.

\title{
Problematizing 'Lazy Robert'
}

In the Danish study, all interviewees expressed that they had encountered RN and the closely linked symbol 'Lazy Robert' through the media. When the author presented each interviewee with the photograph, the image evoked various reactions and comments, including frustration, joking and laughter. The most common reaction to the image was to question RN and 'Lazy Robert' as representative of Danish welfare recipients. As Line (a caseworker, in her twenties) and Anne (a welfare recipient in her forties) say:

\begin{abstract}
Well, he (RN) has become an illustration of the (unemployed) citizens in some way, and he has become an illustration of the majority of the people who are in the (unemployment) system, and I think that this is tremendously wrong. (Line)

$\mathrm{He}(\mathrm{RN})$ is being used in all sorts of ways, right, well (sighs) (...) Then, all cash-benefit recipients are perceived as Lazy Robert. (Anne)
\end{abstract}

The interviewees directly or indirectly questioned RN's generalizability. The accounts reveal widespread frustration with the media's and politicians' use of $\mathrm{RN}$ as a symbol of all welfare recipients. Even before being presented with the image of $\mathrm{RN}$, several interviewees discussed public opinion which they perceived as viewing welfare recipients as lazy. In the media, $\mathrm{RN}$ was presented as a person whose problems were laziness and a lack of a good work ethic. Several interviewees, however, questioned RN's health.

Well... I think he must have Asperger's syndrome or some kind of mental disorder (laughs). (...) He is good at getting people's attention, but he isn't... I don't know... What I primarily think is that both him and the Carina case and the whole poverty debate and the lazy people... It simply isn't right. It isn't representative for the people in job centres (...) And I think that Robert is not mentally right. (...) I think it is awful that the people that are so exposed and ashamed and have had so few chances in life of making a good life, that they are being misused and thought of as being lazy. As far as I know, there are no people who wish for a bad life, but you don't have a good life being on cash benefits. (Thea)

Here, Thea (a caseworker in her fifties), problematized a premise implicit in perceptions of the symbol of 'Lazy Robert', namely, that through receiving welfare benefits a person can live on other people's efforts and not encounter problems. When describing RNs appearance in the media, interviewees used words such as 'sad', 'tragic', and 'tragicomic', indicating that they did not support his view of his 'right to be lazy' to cite the title of Lafargue's (1907) famous contribution to the discussion on the role of work in society (1907). The interviewees questioned the media's and politicians' use of 'Lazy Robert' as a representative symbol of all welfare recipients, because the interviewees considered RN's unwillingness to work as atypical and extreme. 
One interviewee, however, stated that the media had misunderstood RN. Joergen (a welfare recipient in his fifties) questioned RN's health, as did most interviewees, but he also presented RN as a system critic pointing out flaws about labour market policies whose points were obscured in the public debate.

Well, there may be a tad of laziness in him, but what he tried to say, which still hasn't been in focus (in public debate), was very important. Because he was saying that he did not want to be sent out to create unemployment (...) It was exactly this peculiar job scheme (workplace activation) where one can get tossed into unpaid labour, and he (RN) would not do that, and I thought that he was absolutely right. But, as a person, well, I have heard him talk many times. He is probably not a sound person. He is not exactly my cup of tea. I like people better who want to do something. He does not want to do anything (Joergen).

Joergen problematized the media's and politicians' conduct in the debate involving RN. On the one hand, he drew boundaries between himself and RN. On the other hand, Joergen's comments were directed at labour-market policies, criticizing parts of the activation system which he believed works against structural job creation. Similarly, Louise (a former welfare recipient in her twenties) criticized the debate concerning RN on a structural level. She also criticized a discourse of individual responsibility while defending RN's choices.

There has been much of the: 'Well one should simply not take advantage of the system', 'welfare scrounger', 'lazy bastard', 'blah blah blah'. Where I'm thinking that: 'Nobody is perfect, right?' (laughs) and if he gets more out of staying at home, there is no problem for me. There aren't enough jobs for everyone anyway. And I also sometimes believe that a society does not just consist of economy. A welfare society means that there is room for people, in my world. (...) We don't know if Lazy Robert will be the next to write a grand literary work because he was allowed to stay at home. Or, he won't, but maybe he has ignited thoughts in someone else who does (Louise).

Louise did not link RN to her own situation as a former welfare recipient. Instead, she criticized the policy of activation. Her account advocated for a generous attitude towards social diversity.

For others, the photograph of RN mobilized discussions of perceived consequences of the media debate. Anne viewed the media debate regarding $\mathrm{RN}$ as causing the stigmatization of welfare recipients.

Well, it isn't him (RN) that is the cause of all this (the debate) ... Liberal Alliance (a Danish political party) has had a bullying campaign in the media, I suppose we could call it that, on how cash benefit recipients are, how useless we are and that we need help with everything. Their rhetoric and their view on humanity and on people (receiving welfare benefits) simply are so degrading (...) I am of course not untouched by it. It is a poor society, I think, when one bullies groups of people, no matter who they are, immigrants or cash-benefit recipients or the handicapped or Jews or whomever (...). It hurts to be looked down upon (Anne).

Following this statement, Anne discussed the consequences of the debates involving $\mathrm{RN}$ and feeling belittled for being a welfare recipient by a stranger whom she encountered leaving a job centre. We found that Anne and other interviewees problematized not only the discourse of individual responsibility 
but also the potential and experienced stigmatizing effects of the symbol of 'Lazy Robert' being used in this discourse. We address this further in the discussion.

\section{Problematizing 'Faster Back'}

The accounts following the presentation of RN's photograph in the Danish study evoked the interviewees' emotions, thoughts, and opinions related to the specific public debate ignited by RN's statements. In contrast, most of the Norwegian interviewees' had not seen the 'Faster Back' advertisement prior to the interview. Additionally, unlike the photograph of RN, the advertisement was not associated with a specific debate or viewpoint and was therefore open to various interpretations. Erna (a welfare recipient in her forties) and Aslaug (a welfare recipient in her fifties) questioned the most basic message of the NAV advertisement.

\footnotetext{
Oh, wow! Well it's not just the arm that hurts in my case! (laughs heavily). Oh my god, this was some...(illustration). (...) No I feel... oh my good... it's not just the arm for me, that's for sure. Is it possible to distinguish between the arm and (the rest of the body)...? (Erna)

The first reaction is that it's seldom only the arm that hurts if it hurts badly. Then, it spreads to the cerebellum and other places too. (...) If you're in pain then it's impossible to limit it to the arm (Aslaug)
}

Neither Erna nor Aslaug had seen the advertisement prior to the interview. Both women commented on and questioned the illustration, its title, and its written message. Neither interviewee elaborated on their thoughts regarding the media side of the campaign; elsewhere in the interviews, however, they both commented on the stereotyping effects of media presentations of welfare clients' problems.

A strikingly different response was activated in the interview with Bjarne (a welfare recipient in his sixties). Before his encounter with NAV, he had worked in a company in which he was a partner. When shown the advertisement, his thoughts went to his own experiences regarding sick leave.

(Laughs) I have been on sick leave one time (prior) in my life. When I broke my foot, as I told you. That's many years ago now; it's nearly forty years ago. Then, I cycled to work with one foot. With cast on it. And then I got yelled at for going to work when I was on sick leave. (...) But... In the firm I worked in recently... There, we had those kinds of people that were on sick leave and stuff.... All the time (...) and that is bothersome. It is people who exploit it. It's horrible. And it's almost impossible to sack them. Yeah. So there's of course a whole range of freeloaders in our society. I will call many of those that continuously are on sick leave on Mondays and stuff, freeloaders. I don't tolerate that. But if they are away one day when the flu ravages, that's fair enough. But when they're on sick leave because their hair hurts, or their stomach hurts, or... that's totally reprehensible. But that's how it has become: it is easy to get sick leave (Bjarne).

Bjarne did not comment on the campaign. Instead, he discussed his own experiences related to sick leave and the legitimacy of people on sick leave. Anchored in his own experiences as an employer, he questioned other people's work ethic. The account represents accusations of people claiming sick leave 
benefits as being freeloaders and slackers. Furthermore, Bjarne did not seem to relate potential questioning of others' practices to his own legitimacy of receiving welfare benefits.

On a related, yet distinctly different note, Mona (a part-time welfare recipient in her forties), interpreted the advertisement as questioning welfare recipients' work ethic. Mona's response should be seen in light of her suffering from diabetes and facing a lack of sleep caused by hypoglycaemia. She found it difficult to continue full-time employment. Mona was the only interviewee who had seen the Faster Back advertisement prior to the interview. Being shown the image triggered a strong emotional response as well as a rich and complex account of her ambivalent feelings towards receiving benefits.

You know, for me, it's the whole body that hurts, if you know what I mean. Because it has something to do with ... when you're, let's say that I on average have hypoglycaemia one night... every damn week... (Starts to cry). (...) I think it's complicated being on sick leave. Because first, I used a long time to adapt that you're on sick leave and not be ashamed. Because in my family, it's like that you work till you kick the bucket.

Interviewer: Strong work ethic?

Yes! Extremely hard work ethic. I actually told my parents for several months that I was employed in 80 per cent, because I didn't manage to tell them that I was on sick leave for 20 per cent. Because it felt so shameful (Mona).

The interviewer presenting the advertisement to Mona evoked a strong emotional response from her (crying) and an account relating to her family values, as well as her coping strategies at work. She discussed the work ethic in her family and how her parents expected her to help them paint their house when they were told she was on sick leave, which they apparently viewed as spare time. She then mentioned an episode where her father proudly told a story about Mona finishing primary school without taking a single sick day. Mona commented that she remembered throwing up on the way to school after throwing up all night, and then her father said: 'But you made it, Mona!'

You see? It wasn't an option to lie down and feel sick unless you were almost dying. So it's... Of course, you don't want a society where people are shirkers. But the campaign that NAV runs in the media makes you feel even more miserable (Mona).

Similarly to Bjarne, Mona discussed her own experiences and memories when confronted with the advertisement. Another similarity between the two interviewees is that they are both influenced by strong work ethic, although these ethics were arguably formed by strikingly different experiences. For Mona, the image presented in the interview obviously evoked strong emotions concerning her own experiences. This recall led her to problematize the NAV campaign. There is a link in her account between the campaign's message of individual responsibility and her father's apparent attitudes relating to a strong work ethic. However, we interpret the Faster Back image as ambivalent; it has both an inclusionary and a moralizing message. This ambivalence is activated in the interview with Mona. Her account provides insight into the award-winning 'Faster Back' campaign as also potentially stigmatizing its audience. 


\section{Non-problematizing}

Although the analysis uncovered different types of problematizing in the two sets of data, there were also two interviews in which the concept of problematizing does not easily fit as a sensitizing tool. We consider it an important analytical point to examine variations found in our data; therefore, we also include the accounts of the two interviewees who did not 'take the bait'. First, Jonas (a welfare recipient in his thirties) gave the following response when shown the 'Faster Back' advertisement:

Well... Actually I think it's quite okay. Yes. I kind of come from the advertisement industry myself. I think it's a decent presentation. You get an eye-catcher with all these arms. $\mathrm{Hm}$, the text is tiny, but the headline is visible though. I don't think it is too bad (Jonas).

Here, Norwegian interviewee Jonas discusses his own professional background of working in the advertisement industry as he evaluates the image. He judges the image from a technical-professional rather than a normative standpoint. The last of the two interviewees reacting differently to the image than the other interviewees is Christian (a welfare recipient in his forties). Christian was the only participant in the Danish study who did not immediately recognize and react to the photograph of RN. The interviewer followed up by asking him whether he was familiar with the media debates on 'Lazy Robert'. He recognized the label but placed RN in the context of his later participation in a reality-television programme.

I haven't really heard that much about him. (...) Wasn't he a participant in Robinson or something like that? (...) That was where it popped up that he was so lazy or something. I did not watch it, but I believe it was Robinson he participated in (Christian).

In the aftermath of the media and public debate, RN became somewhat of a national celebrity. He participated in several television programmes, including the reality programme the Robinson Expedition, which was adapted from the American television concept 'Survivor'. However, Christian was the only interviewee to link RN primarily to his subsequent television appearances. Neither Jonas nor Christian connected the image they were shown with the moral dimensions implicit in it, unlike the other interviewees who indirectly or directly made the connection. We interpret this difference as related to the activation of a professional perspective (Jonas) and not having encountered the specific media portrayal of RN (Christian).

\section{Discussion and conclusion}

In our merged study, we asked welfare recipients to react to images which relate to discourses of individual responsibility and which potentially contribute to 'othering' of welfare recipients through stereotypes (Lister, 2004). The discussion that follows is to be viewed in light of that our data material is limited in scope. Still, we emphasize that the commonalities found in the analysis, despite the use of dissimilar images and seeing ample variation in responses, are interesting to discuss further in light of reactions to stereotypical portrayals of welfare recipients' work ethic and deservedness, and integrating PE and other visual methods into empirical investigations of 'othered' citizens.

Our analysis shows that most interviewees in both national contexts in a nuanced manner problematize the stereotypes targeting and affecting them. 
Despite taking place in two national contexts, and being presented with dissimilar images, our interviewees discussed much the same themes. The respondents discussed the images' motif surrounding welfare debates, and what they interpreted as the expectations the images conveyed of welfare recipients' responsibility and work ethic. Repeatedly, and related to both images, most of the interviewees either discussed directly the symbols of work ethic and deservedness and its consequences for themselves and others or they discussed these themes indirectly through associations, personal narratives, experiences, and values. Even zooming in on a relatively narrow data material we discovered, in both research contexts, interviewees directly or indirectly discussed the image, stereotypes, stigma, and the role of portrayals of how welfare recipients should and should not act. This finding supports our assumption that the discourse and stereotypes work through the NAV advertisement and the photograph of $\mathrm{RN}$.

One question which arises with the analysis of the PE data concerns the possible effect of PE as a particular methodological strategy for generating responses. According to Harper (2002, p. 3), the contribution of PE to the interview can be substantial because 'the parts of the brain that process visual information are evolutionarily older than the parts that process verbal information'. However, although we do not question the insights related to this, we view it as likely that similar findings from our study could have emerged using other methodological approaches that may create similar methodological 'spaces', such as focus-group interviews. It is important to note, however, that the two images create different processes of response. In the Danish case, in which the context of the media debate surrounding the image is treated as more important than the image itself by the interviewees, the interviewees discussed and problematized the symbol of 'Lazy Robert', not the photograph of RN itself. They problematized the stereotypical portrayal of welfare recipients having a poor work ethic as they experienced it in the debate surrounding the symbol of 'Lazy Robert' being used as a representative of all welfare recipients. In the Norwegian study, the image opened for more variation in responses. This could be related to the Norwegian image being ambiguous and open to various interpretations and associations, though the Norwegian interviewees often discussed the same themes of the stereotypical portrayals of welfare recipients as the Danish interviewees. Reviewing the PE literature, Harper (2002) describes different versions of PE. He sees the selection of photographs and images as following a continuum ranging from (1) 'visual inventories of objects, people and artifacts' that can be used in interviews as direct representations, via (2) images that can be used to elicit memories of collective or institutional experiences, to (3) images related to intimate or emotional dimensions of the self and the social (Harper, 2002, pp. 13-14). We see our images as related to all three points, but perhaps more importantly, we see our study as a highly specific PE approach among many possible ones. Using other types of visual methodological approaches could likely generate both similar and differing findings. As with all social research, findings also depend on the choice of analytical perspective.

Related to the potentially sensitive nature of the themes associated with the images for our interviewees, we examined whether the responses to the images are likely to be influenced by self-presentation. Indeed, some of the replies can be seen as elements of 'self-defence', as described by the literature on 'accounts' (Scott \& Lyman, 1968). Introducing the images gave rise to the problematization of not only the discourse of individual responsibility, but also of others' work ethic. These accounts may be understood as containing elements of lingual self-defence practices by interviewees who justify their own status as unemployed or ill and by distancing themselves from 'others' whom 
they perceive have a deviant work ethic. We conclude, however, that to interpret these responses purely as lingual self-defence strategies would imply too narrow a perspective. Not only do the interviewees defend their own (or, concerning the caseworkers, their welfare recipients') status as welfare recipients, they also engage in nuanced discussions of broader welfare discourses and their consequences for citizens and society, including points of view formed by personal experiences and broader normative orientations of justice. These findings from our study are in line with Fink and Lomax (2012) and Ortega-Alcàzar \& Dyck (2012), who view using PE interviews as a means of obtaining new insights by exposing individuals to images that target them. In most of the reactions to the images, we identify logics of justice. On the one hand, these logics are linked with normative perceptions of obligations of the welfare state and welfare recipients. On the other hand, they are connected with insights into human beings' situations as being more complex than what is portrayed by potentially stereotypical images channelling work ethic and deservedness of welfare recipients.

Debates on welfare benefits, sick leave, poverty, and so on, are often dominated by experts, media commentators and policy-makers, while the voices of those at the frontlines of welfare institutions are often marginalized (e.g., Beresford \& Croft, 1995; Devereux, 1998). Discussing images with interviewees can contribute to challenging traditional hierarchical structures (Fink \& Lomax, 2012) between, for example, the sender of the image and the recipient. Consistent with this we found that the images gave rise to the problematization of stereotypical perceptions and depictions of welfare recipients. Through PE interviews we enabled accounts of micro-narratives challenging the visual narratives in which specific groups are depicted and targeted by government organizations, policy-makers, and media institutions. In conclusion, we found $\mathrm{PE}$ to be a useful methodological tool that enabled interviewees to reply to images targeting them, and giving voice to problematizations of stereotypical portrayals of welfare recipients. We hope to see more studies introducing these non-linguistic dimensions into research interviews with 'othered' citizens.

\section{Acknowledgements}

The authors wish to thank Robert Nielsen for volunteering for the photograph and Henrik Moberg Jessen Photography for taking the photograph and granting us permission to use it in print. Furthermore, we wish to thank the two anonymous referees, Anna S. Bach; Morten Hammerborg; Hans-Inge Hansen; Margaretha Järvinen; Jorunn Mjøs; Hogne Sataøen;and the participants at article discussion sessions at SFI - The Danish National Centre for Social Research; Department of Sociology, University of Copenhagen; and the research group 'Health, welfare, and citizenship', Uni Research Rokkan Centre for providing valuable comments on the manuscript.

\section{References}

Austin, J. (1957). A plea for excuses: The presidential address. Proceedings for the Aristotelian society, 57(1956-1957), 1-30.

Bagnoli, A. (2009). Beyond the standard interview: The use of graphic elicitation and arts-based methods. Qualitative research, 9(5), 547-570.

Barthes, R. (1981). Camera lucida: Reflections on photography. New York: Hill and Wang. 
Beresford, P. \& Croft, S. (1995). 'It's our problem too': Challenging the exclusion of poor people from poverty discourse. Critical social policy, 44/45, 75-95.

Blumer, H. J. (1969). Symbolic interaction: Perspective and method. Berkeley: University of California Press.

Cruikshank, B. (1999). The will to empower: Democratic citizens and other subjects. Ithaca: Cornell University Press.

Daley, S. (2013, April 20). Danes rethink a welfare state ample to a fault. New York Times.

Devereux, E. (1998). Devils and angels: Television, ideology and the coverage of poverty. Luton: University of Luton press.

DR (2012, September 21). Thorning vil saette Dovne Robert paa plads [Thorning wants to put Lazy Robert in his place]. http://www.dr.dk/Nyheder/Politik/2012/09/21/0921065353.htm Danish Broadcasting Corporation (DR)'s news site

DR (2012, September 8). Kontanthjælpsmodtager: Hellere det end pedel i McDonalds [Welfare-benefit recipient: I prefer this to being a janitor at McDonald's]. http://www.dr.dk/Nyheder/Indland/2012/09/06/215200.htm Danish Broadcasting Corporation (DR)'s news site

Fink, J. \& Lomax, H. (2012). Inequalities, images and insights for policy and research. Critical social policy, 32(1), 3-10.

Goffman, E. (1969). The presentation of self in everyday life. London: Penguin.

Grosvenor, I. \& Hall, A. (2012) Back to school from a holiday in the slums!: Images, words and inequalities. Critical Social Policy, 32, 11-30.

Harper, D. (1988). Visual sociology: Expanding sociological vision. The American Sociologist, 19(1), 54-70.

Harper, D. (2002). Talking about images: a case for photo elicitation. Visual studies, 17(1), 13-26.

Hedegaard, T. F. (2014). Stereotypes and welfare attitudes: a panel survey of how 'poor Carina' and 'lazy Robert' affected attitudes towards social assistance in Denmark. Nordic Journal of Social Research, 5, 139-160.

Järvinen, M. (2001). Accounting for trouble: Identity negotiations in qualitative interviews with alcoholics. Symbolic Interaction, 24(3), 263-284.

Lafargue, P. (1907). The right to be lazy. Chicago: Charles Kerr.

Larsen, C. A., \& Dejgaard, T. E. (2012). The institutional logic of images of the poor and welfare recipients. A comparative study of British, Swedish and Danish newspapers. Journal of European Social Policy, 23(3), 287-299.

Lister, R. (2004). Poverty. Cambridge, UK: Polity Press.

Lundberg, K. (2012). Uforutsigbare relasjoner. Brukererfaringer, Nav-reformen og levd liv [Unpredictable relations: User experiences, the Nav reform and lived life]. PhD thesis; Department of Sociology, University of Bergen

Margolis, E. \& Pauwels, L. (eds.) (2011). The SAGE handbook of visual research methods. Los Angeles: Sage.

Martin, W. (2012). Visualizing risk: Health, gender and the ageing body. Critical social policy, 32(1), 51-68. 
Mik-Meyer, N. \& Villadsen, K. (2012), Power and Welfare: Understanding Citizens' Encounters With State Welfare. London: Routledge.

Orbuch, T. (1997) People's accounts count: The sociology of accounts. Annual review of sociology, 23, 455-478.

Ornelas I. J., Amell, J., Tran, A. N., et al. (2009). Understanding African American men's perceptions of racism, male gender socialization, and social capital through photovoice. Qualitative Health Research, 19(4), 552-565.

Ortega-Alcàzar, I. \& Dyck, I. (2012). Migrant narratives of health and well-being: Challenging 'othering' processes through photo-elicitation interviews. Critical social policy, 32(1), 106-125.

Pinholt, K. (2012, March 27). Dovne Robert: Jeg har laert, at jeg godt kan vaere med. [Lazy Robert: I have learned that I can participate]. Danish Broadcasting Corporation. Retrieved from: http://www.dr.dk/Nyheder/Indland/2012/12/23/142426.htm

Radley, A. \& Taylor. D. (2003). 'Images of Recovery: A Photo-elicitation Study on the Hospital Ward', Qualitative Health Research 13(1), 77-99.

Rose, G. (2012). Visual methodologies. London: Sage.

Scott, M. B. \& Lyman, S. M. (1968). 'Accounts'. American Sociological Review, 33(1), 46-62.

Silverman, D. (2001). Interpreting qualitative data: Methods for analysing talk, text and interaction. London: Sage.

Spencer, S. (2011). Visual research methods in the social sciences: Awakening visions. London: Routledge. 